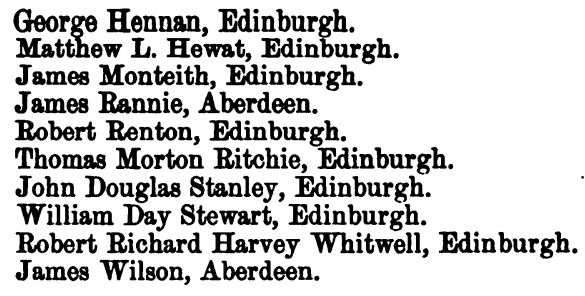

IRELAND.

JUNE, 1889.

Examiners :

Dr. Ringrose Atkins and Dr. Conolly Normas. PASS EXAMINATION.

Carlo Raymond Zimmer, M.B., B.Ch., B.A.O., of the Royal Tniversity of Ireland.

N.B.-The questions asked in these Examinations will be printed in the next number of the Journal.

The next Examination for England will be held at Bethlem Hospital in December. For other particulars, and for the Scotch and Irish Examinations, apply to the Secretaries, as given in the list of Officers and Members at the end of this number.

Correspondence.

\title{
ON THE USE OF RESTRAINT IN THE CARE OF THE INSANE.
}

\section{To the Editors of the "Jodrnal of Mental Sorewom."}

Gentlames,-The questions which interest the public, lay and medical, in this discussion, are : Has there been a return to any considerable extent in the treatment of the insane in the asylums of the kingdom to the use of instruments of restraint which had been all but abandoned? and, if so, Have the results of reverting to old methods been so satisfactory as to fully justify this retrograde step? A mere expression of opinion on the part of any physician that he considers restraint necessary in certain cases is of little moment in the determining of the latter question; for it is evident that another medical man, who approves of the non-restraint principle, may succeed in treating such cases to a successful conclusion by other means. I presume that the most resolute advocates of restraint in its cruellest forms and darkest days would advance similar reasons for their practice-would maintain that the use of these instruments was indispensable in certain cases, and would also object to any interference with their liberty of action. However, more is required than opinion; the question must be submitted to the stern logic of facts.

It was a conviction that a comparison of results by the advocates of the minimum, and those of the more extended use of restraint was 
the sonndest basis of a correct conclusion, that led me to state my own experience in detail, and to invite Dr. Yellowlees, or other physician who coincided in his views, to record his also. But Dr. Yellowlees appears to think that such a comparison has no bearing on the question. He actually declares that the details of my life's experience in the treatment of the insane with the use of what he obviously regards as an objectionable minimum of restraint " are quite irrelevant!" Had he said that he did not find it convenient or advisable to submit such a return, I could have appreciated his position, but how he can hold that it would be irrelevant is to me incomprehensible. On the contrary, I can assure him that nothing could be more relevant, and that $a$ full and frank statement of the results of his experience with the considerable use of mechanical restraint which he recommends would be a valuable contribution towards the forming of a correct judgment on the subject

I hope that Dr. Yellowlees will still see fit to publish the results of his experience, and in the same form as I submitted mine in the April number, so that it may be practicable to institute a fair comparison between the two systems of management. To help him to see that such details are thoroughly relevant, I shall briefly refer to the leading ones in my statement in relation to the four classes of the insane in whose treatment he thinks restraint is justifiable. However, as the Doctor is of opinion that I failed to state his views accurately, I shall again quote his own words from his speech at the Edinburgh meeting at somewhat greater length than I did in my former letter. He said, "In what cases is restraint justifiable? Of course, much depends on the personal opinion of the medical attendant. I think it is justifiable, (1) *In cases where the suicidal impulse is intensely strong. I have no hesitation whatever in putting gloves on these patients, for their own safety and the protection of the attendants in charge of then. (2) In cases of extreme and exceptional violence. I think the use of gloves often wise in such cases. Once or twice I have used side-arm dresses, though not for many years. (3) In exto emely destructive cases. I do not think that a heap of rags over the room is a thing to be proud of for the patient's good. To those I add (4) .... the helpless and incessantly restless patients. . . . The protection bed which Dr. Lindsay, of Perth, thought so highly of may be useful in these cases instead of restraint. I remember two cases where this mode of treatment was extremely valuable."

In illustration of his practice, he remarked in the course of his speech: "Four of my patients wore gloves last night, and I do not see the shadow of a reason why, if gloves seem desirable, a patient should not wear them."

It is clear, then, that Dr. Yellowlees is of opinion that, by the use of locked gloves, there is a special safeguard against suiciàe, homicide, or dangerous violence, and the acts of destructive patients. I

* The Italio are his. 
ask him then to tell us if his experience shows an immunity from homicide, suicide, or serious injury to patients or attendants greater than that of those who adhere to the non-restraint principle. And also, if he has succeeded by their use in preventing destruction of clothing and glass, or can, at least, show less expenditure for these articles over such a period as a year, than those who do not order gloves for destructive patients.

Surely Dr. Yellowlees will not continue to contend that these questions are "quite irrelevant." Besides holding that they are quite relevant, I am of opinion that the other points of my statement are so also; for it might be supposed that the complete immunity from homicide, suicide, and permanent injury of attendants or patients, which my experience shows was obtained through the supervision of a disproportionate number of attendants, and a generally higher expenditure for management than in Gartnavel, or other asylum where restraint is more freely used. Therefore it seemed to me necessary to mention the weekly cost of patients, the proportion of attendants, rate of recovery, etc., in the establishment under my charge, in order that a full and fair comparison might be made of an asylum conducted with the present minimum, and those managed with the present maximum use of restraint.

Dr. Yellowlees nakes light of my reference to the foundation-stone of Gartnavel Asylum. I can assure him from my own recollection that the laying of it was the occasion of a solemn religious service, and was taken part in by the leading and most respected men of an all but by-gone generation belonging to the West of Scotland. Its special feature was, undoubtedly, the tablet in the hollow of the stone bearing the inscription which I quoted, namely, that the asylum now under his charge was erected on the principle "of emploging no mechanical personal restraint in the treatment of the patients." When Dr. Yellowlees has seen fit to depart distinctly and definitely from that principle, and thus given it as his opinion that these men were in error, surely, if for no other reason, the high motives by which they were actuated called for a more respectful reference to their work. But he has yet to show that they were in error.

16, Newton Terrace, Glasgow,

ALEX. ROBERTSON.

August 26th, 1889.

To the Editors of the "Journal of Mental Soirnow."

GentLemen,-By your courtesy in sending me a proof copy, I am enabled to reply at once to Dr. Robertson's second letter.

To say that I recommend and practise " the considerable use of mechanical restraint" is a total misrepresentation, which should have been impossible to anyone who read my words in the Journal. If locked gloves be referred to, which are not "mechanical restraint" and which the Commissioners do not regard as such, the statement is 